\title{
Work-relatedness of lumbosacral radiculopathy syndrome
}

\author{
Review and dose-response meta-analysis
}

P. Paul F.M. Kuijer, PhD, Jos H. Verbeek, MD, PhD, Andreas Seidler, MD, PhD, Rolf Ellegast, PhD,

Neurology ${ }^{\circledR}$ 2018;91:558-564. doi:10.1212/01.wnl.0000544322.26939.09

\author{
Correspondence \\ Dr. Kuijer \\ p.p.kuijer@amc.uva.nl
}

\begin{abstract}
Objective

Clinicians need to know whether lumbosacral radiculopathy syndrome (LRS) can be attributed to work. This review describes what work-related risk factors are associated with LRS.
\end{abstract}

\section{Methods}

A systematic review was performed in PubMed and Embase. Inclusion criteria were that LRS was diagnosed by a clinician and workers exposed to work-related risk factors were compared to workers less or not exposed. A quality assessment and a meta-analysis were performed, including a dose-response analysis.

\section{Results}

The search resulted in 7,350 references and 24 studies that fulfilled the inclusion criteria: 19 studies were rated as having a high risk of bias and 5 as having a low risk of bias. The median number of LRS patients per study were 209 (interquartile range 124-504) and the total number of participants was 10,142. The meta-analysis revealed significant associations with heavy physically demanding work (odds ratio [OR] 2.03, 95\% confidence interval [CI] 1.48-2.79), bending or twisting of the trunk (OR 2.43, 95\% CI 1.67-3.55), and lifting and carrying in combination with bending or twisting of the trunk (OR 2.84, 95\% CI 2.18-3.69). No significant associations were found for professional driving (OR 1.46, 95\% CI 0.90-2.35) or sitting (OR 1.08, 95\% CI 0.49-2.38). A dose-response relation was present per 5 years of exposure for bending (OR 1.12, 95\% CI 1.04-1.20), lifting (OR 1.08, 95\% CI 1.02-1.14) and the combination of bending and lifting (OR 1.14, 95\% CI 1.01-1.29).

\section{Conclusions}

Moderate to high-quality evidence is available that LRS can be classified as a work-related disease depending on the level of exposure to bending of the trunk or lifting and carrying. Professional driving and sitting were not significantly associated with LRS. 


\section{Glossary}

CI = confidence interval; GRADE = Grades of Recommendations, Assessment, Development and Evaluation; LRS = lumbosacral radiculopathy syndrome; MEVORECH = Methodological Evaluation of Observational Research; OR = odds ratio.

Knowledge regarding the work-relatedness of lumbosacral radiculopathy syndrome (LRS) is of importance for patients and clinicians in order to answer questions regarding prevention and medical causation. For effective prevention, a prerequisite is knowing whether work-related risk factors indeed matter in the onset of a disease. ${ }^{1}$ An exposure dose-response relationship increases our confidence in the causality of the association. ${ }^{2}$ In addition, if data allow, clinically relevant threshold limits can be formulated. ${ }^{3,4}$ Regarding medical causation, many countries provide financial compensation when LRS is recognized as an occupational disease, like the Unites States, Canada, and half of the countries in the European Union, including Italy, France, and Germany. 5,6 However, the particular decision criteria for this clinical assessment differ among countries. ${ }^{5,6}$ No systematic review or meta-analysis is available that answers this etiologic question regarding work-related risk factors for LRS. Therefore, the 2 aims of this review were to assess whether (1) work-related risk factors are associated with clinically assessed LRS and (2) a positive dose-response relationship is present.

\section{Methods}

The systematic review and meta-analysis was performed in line with the criteria of the PRISMA statement ${ }^{7}$ and was registered by the international prospective register of systematic reviews (PROSPERO, crd.york.ac.uk) with the registration number CRD42015025763.

\section{Inclusion criteria}

The following inclusion criteria were used: the study was written in English or German; the study presented original data; participants were workers; LRS was diagnosed by a clinician without taking into account the diagnostics tests used; work-related risk factors were described, for instance, in terms of job or occupation, physical workload, or specific occupational activities like lifting, or movements or postures like bending of the trunk. To get a good overview of the present data, all study designs were included as long as the data were described in terms of LRS present or not, and exposure was described in terms of exposed/less or nonexposed. In addition, for the meta-analysis, we included self-reports about exposure, researcher observations, or direct measurements if at least 2 categories were described: exposed vs less or nonexposed regarding workers with or without LRS.

\section{Literature search}

Systematic literature searches were performed using PubMed and Embase, both until March 29, 2017. The search strategy involved combining searches for "lumbosacral radiculopathy syndrome," terms for work-related exposure, and the Yale etiologic filter for epidemiologic studies on risk factors. The specific terms used in both databases are available in Occupational Diseases (appendix e-1, occupationaldiseases.nl/content/LRS).

\section{Study selection}

After duplicates from PubMed and Embase were removed, 2 reviewers (P.P.F.M.K., H.F.V.d.M.) independently checked the fulfilment of the inclusion criteria. We first screened titles and abstracts and excluded studies that obviously did not fulfill the inclusion criteria. Of the remaining references, we obtained the full text and assessed them independently for eligibility based on the full texts. We resolved disagreements by discussion.

\section{Data extraction}

The following data were extracted by one author (P.P.F.M.K.) and independently checked by a second author (H.F.V.d.M.): author, year of publication, country, study design; case definition of LRS; sources of retrieving participants; number and characteristics of participants like sex and age; exposure definition; exposure assessment; occupation of participants; definition of exposure categories; number of workers with or without LRS for the described exposure categories; risk estimate and confidence interval; and adjustment for confounding.

\section{Quality assessment}

Two reviewers (P.P.F.M.K., H.F.V.d.M.) independently checked the risk of bias using a checklist based on the Methodological Evaluation of Observational Research (MEVORECH) - observational studies of risk factors for chronic diseases. ${ }^{8,4}$ Ten categories were scored with 5 categories classified as major domains: exposure definition, exposure assessment, reliability of estimates, confounder assessment, and methods of analyses. The 5 minor domains were reported funding, conflict of interest, blinding, attrition, and selective reporting. Every item was independently scored by 2 reviewers (P.P.F.M.K., H.F.V.d.M.) as high, low, or unclear. Differences in outcome were mutually discussed until consensus was reached.

For the overall score over the 10 domains, we distinguished between studies with a high risk of bias and studies with a low risk of bias. Low risk of bias was arbitrarily defined as a low risk of bias in at least 3 out of the 5 major domains and at least 2 out of the 5 minor domains. In the other cases, the study was rated as having a high risk of bias.

\section{Data analysis}

To answer the first research question, a meta-analysis is performed if risk factors are sufficiently homogeneous across at 
least 2 studies. For each risk factor, the highest vs the lowest exposures as reported in the studies will be used. We calculate a pooled odds ratio (OR) and $95 \%$ confidence interval (CI) for each risk factor using a random effects model in Cochrane's RevMan 5.3, both for the high- and low-risk studies combined and only for the studies with a low risk of bias, if possible. The results are presented as forest plots including the contribution of each study (weight) to the overall effect (Mantel-Haenszel, random) using RevMan 5.3.

For the second research question, a pooled exposure doseresponse analysis is performed for studies that report on more than 2 exposure categories for a work-related risk factor. If these data are available, we will first transform the exposure to a standard metric consisting of a dose per working day in terms of level and duration, for instance handling loads of more than $5 \mathrm{~kg}$ (level) for at least 2 hours per working day (duration). Next, the dose will be described per number of working years that this exposure category was performed. If necessary, authors of included studies that had collected these types of data are contacted to provide their data using these exposure and dose terms. Then we assign an exposure dose to the categories that were reported by the authors and for which they reported LRS risks. Next, we employ the GLST regression technique as described by Orsini et al. ${ }^{9}$ implemented in STATA to calculate the dose-response curve for that study, which is then represented by the incremental OR per years of exposure, again if possible. Finally, we combine these incremental ORs in a random-effects meta-analysis with the RevMan program 5.3 as described above.

\section{GRADE}

The Grades of Recommendations, Assessment, Development and Evaluation (GRADE) framework for prognostic studies was used to assess the quality of evidence for the relationship between the work-related risk factors and LRS that were included in the meta-analyses. ${ }^{10}$ Four levels of quality are used: high, moderate, low, and very low. The starting qualification of the quality of evidence of the studies in the meta-analyses was high given the inclusion of only studies specifically focusing on work-related risk factors. ${ }^{10}$ Next, the quality of evidence was downgraded based on the following 5 factors: study strengths (majority of studies having high risk of bias), consistency $\left(I^{2}>50 \%\right)$, indirectness (a priori not true, given our inclusion criteria that the outcome LRS is diagnosed by a physician), imprecision (range of the CI of studies $>2.0$ ), and publication bias (yes or unclear). Finally, study findings with moderate or large effect sizes (i.e., lower limit of $95 \% \mathrm{CI}$ OR $>2.0$ for studies with a low risk of bias) and the presence of an exposure-response relationship resulted in an upgrade of the quality of evidence. ${ }^{10}$

Figure 1 Flow chart of the included studies

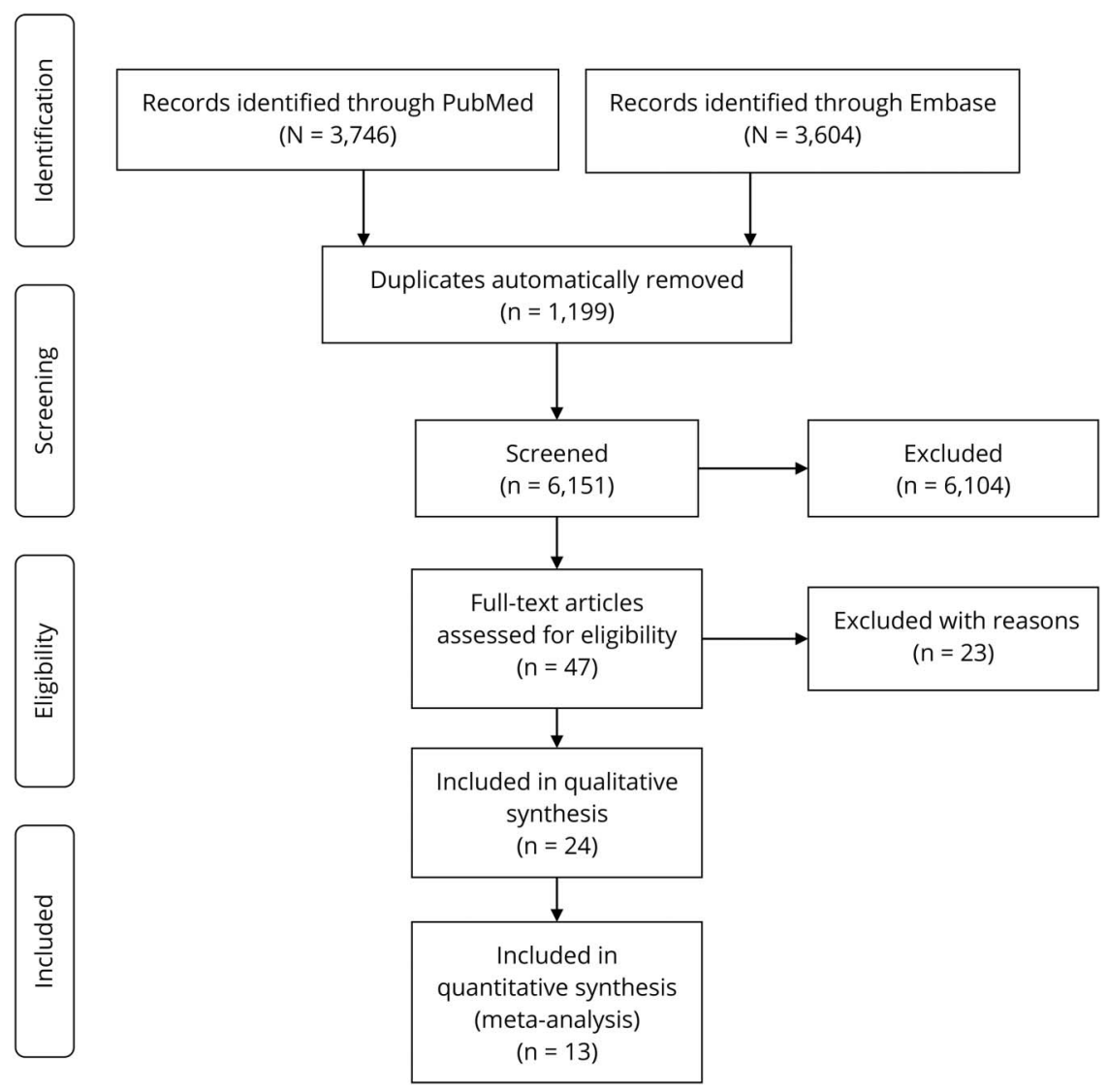




\section{Results}

The search resulted in a total of 7,350 references and after inclusion 24 remained, ${ }^{11-34}$ of which 13 could be used for the meta-analyses because exposure categories were described in terms of occupational activities and not only as job titles (figure 1). ${ }^{11,14,17-20,23,24,27-30,34}$

\section{Description of included studies}

The 24 studies were performed worldwide in 12 countries (number of studies): Bangladesh (1), Bulgaria (1), China (2), Croatia (1), Denmark (2), Finland (6), France (1), Germany (2), Great Britain (1), Sweden (1), Taiwan (1), and United States (5). ${ }^{11-34}$ Two studies were cross-sectional, ${ }^{23,31} 15$ casecontrol, ${ }^{11,13-15,19-22,24,26-29,33,34}$ and 7 cohort. ${ }^{12,16-18,25,30,32}$ The median number of LRS patients per study was 209 (interquartile range 124-504) and the total number of included patients was 10,142. Regarding the 13 studies included in the meta-analysis, 5 studies were rated as having a low risk of bias ${ }^{17,18,24,28,29}$ and 8 as having a high risk of bias ${ }^{11,14,19,20,23,27,30,34}$ (data available from Occupational Diseases) (table e-1, occupationaldiseases.nl/ content/LRS). The studies with low risk of bias all adjusted for differences in age. Other confounders taken into account were sex, body mass index, and smoking. The extracted data are available in Occupational Diseases (appendix e-2, occupationaldiseases.nl/content/LRS).

\section{Work-related risk factors}

The following work-related risk factors (or combinations) were studied (number of studies): job description (9), heavy physical workload (11, of which 1 could not be included in the meta- analyses because data on cases and controls were not reported), lifting and carrying (6, of which 1 could not be included in the meta-analyses because data on cases and controls were not reported), bending and twisting of the trunk (4), lifting and bending of the trunk (2), driving a vehicle or being exposed to whole body vibration (6), sitting without driving (2), physical workload in general and driving a vehicle (1), and kneeling (1).

Data available from Occupational Diseases (table e-2, occupationaldiseases.nl/content/LRS) present the findings of the single studies and the summarized results of the meta-analyses including the definition of the high exposed categories and the reference categories for each risk factor. Heavy physically demanding work is associated with a significantly increased OR of 2.03 (95\% CI 1.48-2.79) for LRS (data available from Occupational Diseases [table e-2 and figure e-1, occupationaldiseases. $\mathrm{nl} /$ content/LRS]). When only studies with a low risk of bias are included, OR is 1.95 (95\% CI 1.39-2.74) (data available from Occupational Diseases [figure e-2, occupationaldiseases.nl/content/LRS]). A significantly increased risk is also present for bending or twisting of the trunk, both for the combined low and high risk of bias studies (OR 2.43, 95\% CI 1.67-3.55) (figure 2) (data available from Occupational Diseases [table e-2, occupationaldiseases.nl/content/LRS]) and for only the low risk of bias studies (OR 2.48, 95\% CI 1.49-4.13) (data available from Occupational Diseases) (figure e-3, occupationaldiseases.nl/content/LRS). For lifting or carrying only, a significant increased risk was present for the low risk of bias studies (OR 1.70, 95\% CI 1. 04-2.78) and not when low and high risk of bias were included (OR 1.41, 95\% CI 0.93-2.14) (data available from Occupational Diseases) (table e-2, figures e-4 and e-5, occupationaldiseases.nl/

Figure 2 Risk of lumbosacral radiculopathy syndrome due to bending and twisting of the trunk based on low risk of bias studies (green dot + ) and high risk of bias studies (red dot - )

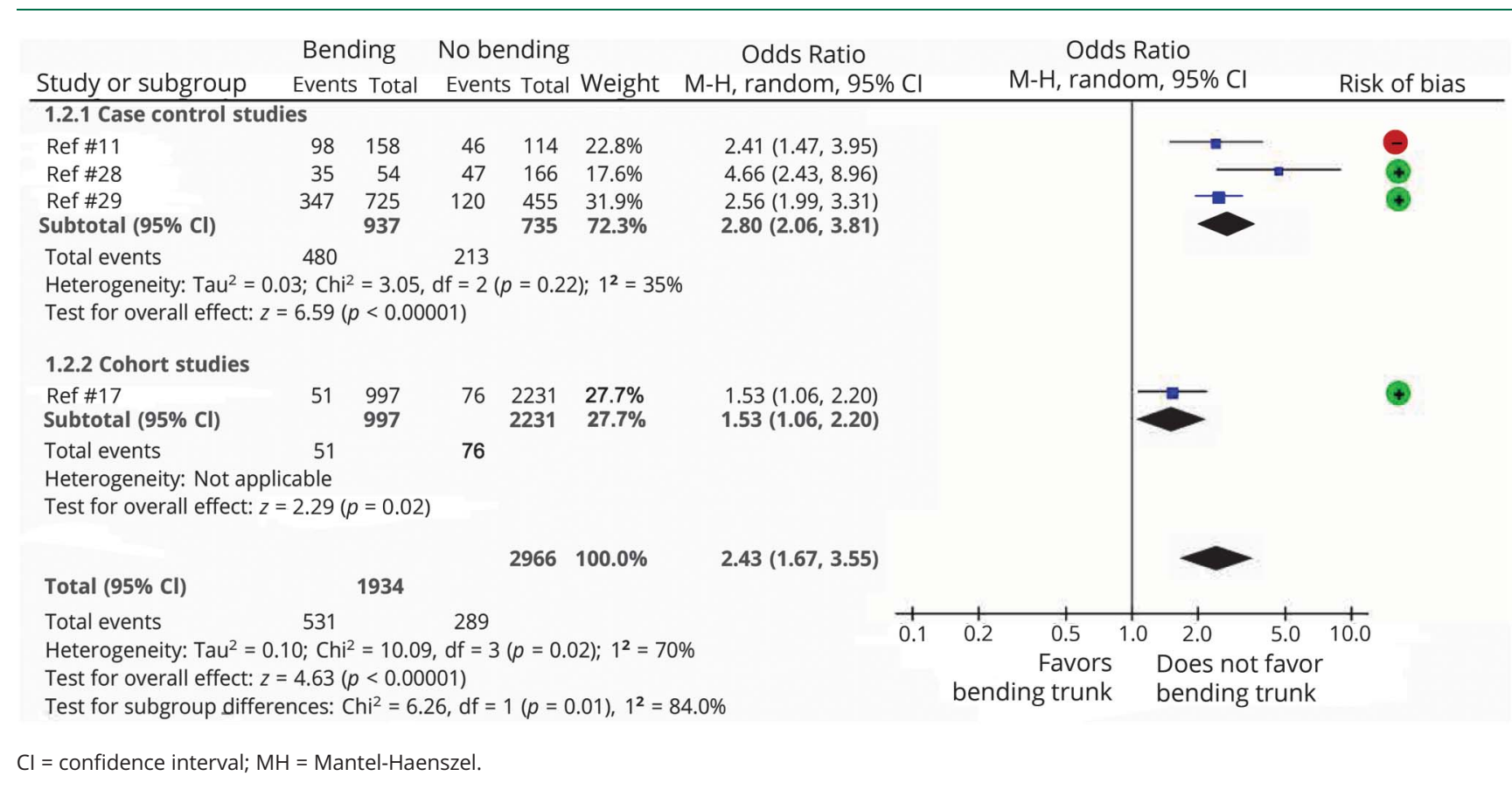


content/LRS). For the combination of lifting and bending of the trunk, 2 studies with a low risk of bias were present and resulted in the highest significant increased risk of all risk factors studied (OR 2.84, 95\% CI 2.18-3.69) (data available from Occupational Diseases) (figure e-6 and table e-2, occupationaldiseases.nl/ content/LRS).

No statistically significant associations were found for professional driving or being exposed to whole body vibration and sitting in the meta-analyses, regardless of the quality of the study data available from Occupational Diseases (table e-2, figures e-7, e-8, and e-9, occupationaldiseases.nl/content/ LRS). The symmetry of the funnel plot suggests no publication bias of the studies included in the meta-analyses (data available from Occupational Diseases) (figure e-10, occupationaldiseases.nl/content/LRS).

\section{Dose response}

One cohort study and 2 case-control studies, all with a low risk of bias, could be included in the meta-analysis to assess the risk in terms of a dose-response relationship per 5 years of exposure. $^{17,28,29}$ A dose-response relation was present for bending of the trunk of $20^{\circ}$ or more for at least 1 hour per work day with OR of 1.12 (95\% CI 1.04-1.20) per 5 years of exposure, for lifting at least $5 \mathrm{~kg}$ for 2 hours per work day or $20 \mathrm{~kg}$ at least 10 times per work day with OR of 1.08 (95\% CI 1.02-1.14) per 5 years exposure, and for the combined exposure to the aforementioned bending and lifting, with OR of 1.14 (95\% CI 1.01-1.29) per 5 years of exposure. An incremental OR of 1.14 means a $14 \%$ increase in LRS per 5 years of exposure. Then, after 10 years of exposure, a significant increased risk is present (OR 1.30 , 95\% CI 1.02-1.66) and after 30 years of exposure, the OR increases to 2.19 (95\% CI 1.06-4.61) (figure 3).

\section{GRADE}

The rating of the evidence for the work-related risk factors included in the meta-analyses varied between "very low" for physical workload and "high" for the combination of lifting and bending of the trunk (table 1). The latter is based on one downgrade for publication bias ("unclear") shifting the overall quality from "high" to "moderate," and 2 upgrades: one for an effect size larger than 2 of the lower limit of the $95 \% \mathrm{CI}$, namely 2.18 , shifting the evidence back from "moderate" to "high," and another upgrade for the presence of a doseresponse relationship. However, the latter upgrade does not result in a higher level of evidence because the GRADE evaluation already has reached the highest value of "high."

\section{Discussion}

This review shows that LRS is associated with risk factors at work, especially if this work consists of lifting and carrying, and bending and twisting of the trunk. The evidence for the combination of both risk factors was of high quality in GRADE terms and substantiated by the fact that low risk of bias studies showed that lifting and carrying itself and bending and twisting of the trunk itself were both
Figure 3 Dose-response relation between the risk of lumbosacral radiculopathy syndrome (odds ratio, including 95\% confidence interval) and number of years bending 20 degrees at least 1 hour a day and lifting $5 \mathrm{~kg}$ during 2 hours per work day or 20 kg 10 times per work based on 3 studies $^{17,28,29}$

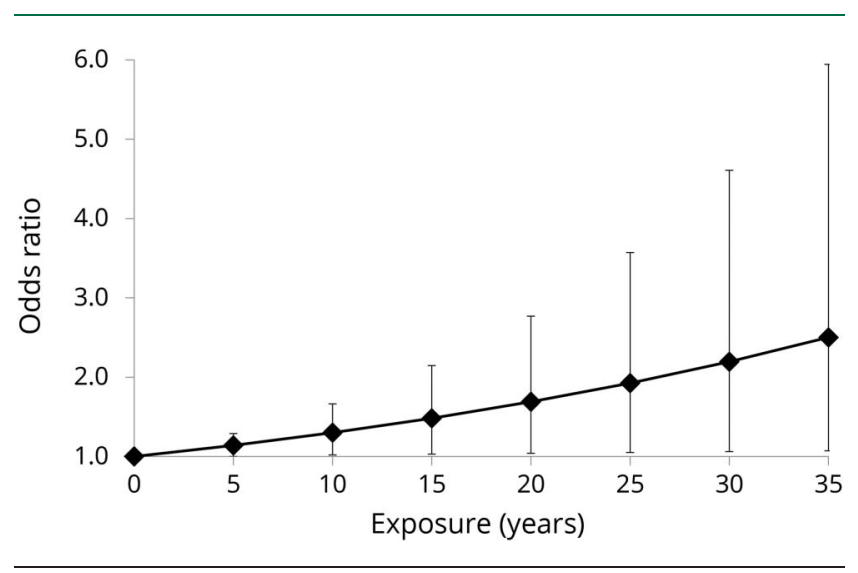

independent risk factors of LRS. This review explicitly substantiates 2 important criteria for the likelihood of causality, namely the presence of a dose-response relationship and a lower limit 95\% CI larger than 2. ${ }^{2,35}$ This overall high quality for the combination of both risk factors implies in wording that "we are confident that the true effect lies close to that of the estimate of the effect." 10 Especially, patients who perform heavy manual labor for more than 10 years including frequent bending of the trunk of more than $20^{\circ}$ for an hour a day in combination with daily lifting of loads of more than $20 \mathrm{~kg}$ more than 10 times per day. These latter workers appear to have a more than twofold higher risk compared to their age-similar counterparts who do not perform this heavy manual labor for more than 10 years including the aforementioned bending and lifting. If true, sufficiently reducing lifting and bending of the trunk of 4 workers-the number needed to prevent-might result in prevention of 1 LRS case. Of course, only intervention studies of good quality can substantiate these assumptions.

In addition, the available evidence suggests that professional driving might not be a risk factor in itself, although future studies presenting new data, preferably using whole body vibration measurements for exposure classification, ${ }^{24}$ might change this point of view given the moderate quality of evidence in GRADE terms. The same goes for sitting at a desk during work, with a low quality of evidence.

A strength of the present review is that meta-analyses were performed including dose-response analyses. This was only possible due to the fact that the authors of 2 of the 3 studies that fulfilled the inclusion criteria were willing to reanalyze their data in the same manner. ${ }^{28,29}$ A second strength of our study is that only clinically assessed patients with LRS were included. A third strength is that we calculated the workrelated risk not only for all included studies but separately for 


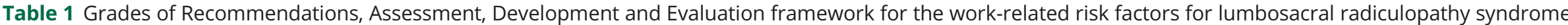
included in the meta-analyses

\begin{tabular}{|c|c|c|c|c|c|c|c|c|c|c|c|c|}
\hline Risk factor & $\begin{array}{l}\text { No. of } \\
\text { participants }\end{array}$ & $\begin{array}{l}\text { No. } \\
\text { of } \\
\text { cases }\end{array}$ & $\begin{array}{l}\text { No. of } \\
\text { studies }\end{array}$ & $\begin{array}{l}\text { Phase of } \\
\text { investigation }(1= \\
\text { explorative, } 2,3= \\
\text { explanatory) } \\
\text { Phase } 1: \downarrow\end{array}$ & $\begin{array}{l}\text { Study } \\
\text { limitations, } \\
\text { majority of } \\
\text { studies high } \\
\text { risk of bias: } \downarrow\end{array}$ & $\begin{array}{l}\text { Inconsistency, } \\
I^{2}>50 \%: \downarrow\end{array}$ & $\begin{array}{l}\text { Indirectness, } \\
\text { Yes: } \downarrow\end{array}$ & $\begin{array}{l}\text { Imprecision, } \\
\text { range, } \\
\text { confidence } \\
\text { interval effect } \\
\text { size }>2.0: \downarrow\end{array}$ & $\begin{array}{l}\text { Publication } \\
\text { Bias, yes or } \\
\text { unclear: } \downarrow\end{array}$ & $\begin{array}{l}\text { Effect size lower } \\
\text { limit confidence } \\
\text { interval in low risk } \\
\text { of bias studies } \\
>2.0: \uparrow\end{array}$ & $\begin{array}{l}\text { Dose- } \\
\text { response } \\
\text { present: } \\
\text { Yes } \uparrow\end{array}$ & $\begin{array}{l}\text { Overall } \\
\text { quality } \\
\text { (high, } \\
\text { moderate, } \\
\text { low, very } \\
\text { low) }\end{array}$ \\
\hline $\begin{array}{l}\text { Physical } \\
\text { workload }\end{array}$ & 15,033 & 1,288 & 10 & 2 & High (6/10) $\downarrow$ & $80 \% \downarrow$ & No & No: $1.48-2.79$ & Unclear $\downarrow$ & $1.93(1.39-2.74)$ & No & Very low \\
\hline $\begin{array}{l}\text { Bending and } \\
\text { twisting of } \\
\text { trunk }\end{array}$ & 4,900 & 820 & 4 & 2 & Low (1/4) & $70 \% \downarrow$ & No & No: 1.67-3.55 & Unclear $\downarrow$ & $2.48(1.49-4.13)$ & Yes $\uparrow$ & Moderate \\
\hline $\begin{array}{l}\text { Lifting and } \\
\text { carrying }\end{array}$ & 4,865 & 763 & 5 & 2 & Low (2/5) & $77 \% \downarrow$ & No & No: $0.93-2.14$ & Unclear $\downarrow$ & $1.70(1.04-2.78)$ & Yes $\uparrow$ & Moderate \\
\hline $\begin{array}{l}\text { Lifting and } \\
\text { bending of } \\
\text { trunk }\end{array}$ & 1,043 & 392 & 2 & 2 & Low (0/2) & $0 \%$ & No & No: 2.18-3.69 & Unclear $\downarrow$ & $2.84(2.18-3.69) \uparrow$ & Yes $\uparrow$ & High \\
\hline $\begin{array}{l}\text { Professional } \\
\text { driving }\end{array}$ & 6,571 & 565 & 6 & 2 & Low (3/6) & $43 \%$ & No & No: $0.90-2.35$ & Unclear $\downarrow$ & $1.23(0.57-2.64)$ & No & Moderate \\
\hline Sitting & 505 & 225 & 2 & 2 & Low (1/2) & $77 \% \downarrow$ & No & No: $0.49-2.38$ & Unclear $\downarrow$ & $0.70(0.37-1.30)$ & No & Low \\
\hline
\end{tabular}


the studies with a low risk of bias. In the latter case, lifting or carrying also appeared to be a significant risk factor for LRS. This stresses the importance of valid and reliable exposure assessments in etiologic studies. This also brings up an important limitation of our review: most studies are unblinded case-control studies using self-reports for exposure assessment, which is an important source for recall bias and possibly overestimation of exposure. For instance, only one study used whole body vibration measurements for exposure classification in the assessment of the risk of LRS due to professional driving. ${ }^{24}$ In addition, we arbitrarily set criteria for low and high risk of bias studies because MEVORECH has no predefined cutoff points. Moreover, given the relatively few studies per risk factor, no reassuring assumption can be made about publication bias. Another limitation of our review is that only 11 studies adjusted for confounding of relevant non-

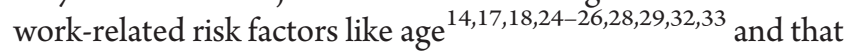
only 3 studies assessed the exposure using other methods than self-reports or interviews to obtain more precise exposure data. ${ }^{24,28,29}$ However, even if other methods than self-reports were applied, cumulative exposure data, especially of trunk bending postures, can only be roughly estimated over long working periods in different occupational tasks.

Moderate to high-quality evidence is available that LRS can be classified as a work-related disease depending on the level of exposure to bending and twisting of the trunk and lifting and carrying in physically demanding work. A policy to prevent LRS should focus on work-related risk factors since no other modifiable risk factors are known and given the probably small number of workers needed for prevention of 1 LRS case.

\section{Author contributions}

Dr. Kuijer, Dr. Verbeek, Prof. Dr. Hulshof, Prof. Dr. FringsDresen, Dr. Van der Molen: study concept and design. Dr. Kuijer, Dr. Van der Molen, Prof. Dr. Seidler, Prof. Dr. Ellegast: acquisition of data. Dr. Kuijer, Dr. Verbeek, Dr. Van der Molen: statistical analyses. Dr. Kuijer, Dr Van der Molen: quality assessments. Dr. Kuijer, Dr. Verbeek, Prof. Dr. Seidler, Prof. dr. Ellegast, Prof. Dr. Hulshof, Prof. Dr. Frings-Dresen, Dr. Van der Molen: critical revision of the manuscript for important intellectual content and approval of final version. Dr. Kuijer, Prof. Dr. Frings-Dresen, Dr. Van der Molen: study supervision.

\section{Study funding}

The work is sponsored by the Ministry of Social Affairs and Employment, the Netherlands.

\section{Disclosure}

The authors report no disclosures relevant to the manuscript. Go to Neurology.org/N for full disclosures.

Received October 3, 2017. Accepted in final form May 25, 2018.

\section{References}

1. Boschman JS, Brand T, Frings-Dresen MH, van der Molen HF. Improving the assessment of occupational diseases by occupational physicians. Occup Med 2017;67: 13-19.
2. Verbeek J. When work is related to disease, what establishes evidence for a causal relation? Saf Health Work 2012;3:110-116.

3. Coenen P, Gouttebarge V, van der Burght AS, et al. The effect of lifting during work on low back pain: a health impact assessment based on a meta-analysis. Occup Environ Med 2014;71:871-877.

4. Verbeek J, Mischke C, Robinson R, et al. Occupational exposure to knee loading and the risk of osteoarthritis of the knee: a systematic review and a dose-response metaanalysis. Saf Health Work 2017;8:130-142.

5. Johanning E. Whole-body vibration-related health disorders in occupational medicine-an international comparison. Ergonomics 2015;58:1239-1252.

6. Laštovková A, Nakládalová $\mathrm{M}$, Fenclová $\mathrm{Z}$, et al. Low-back pain disorders as occupational diseases in the Czech Republic and 22 European countries: comparison of national systems, related diagnoses and evaluation criteria. Cent Eur J Public Health 2015;23:244-251.

7. Moher D, Liberati A, Tetzlaff J, Altman DG, PRISMA Group. Preferred reporting items for systematic reviews and meta-analyses: the PRISMA statement. J Clin Epidemiol 2009;62:1006-1012.

8. Shamliyan TA, Kane RL, Ansari MT, et al. Development quality criteria to evaluate nontherapeutic studies of incidence, prevalence, or risk factors of chronic diseases: pilot study of new checklists. J Clin Epidemiol 2011;64:637-657.

9. Orsini N, Bellocco R, Greenland S. Generalize least squares for trend estimation of summarized dose-response data. Stata J 2006;6:40-57.

10. Huguet A, Hayden JA, Stinson J, et al. Judging the quality of evidence in reviews of prognostic factor research: adapting the GRADE framework. Syst Rev 2013;2:71.

11. Ahsan MK, Matin T, Ali MI, Ali MY, Awwal MA, Sakeb N. Relationship between physical work load and lumbar disc herniation. Mymensingh Med J 2013;22:533-540.

12. Chung YC, Hung CT, Li SF, et al. Risk of musculoskeletal disorder among Taiwanese nurse cohort: a nationwide population-based study. BMC Musculoskelet Disord 2013;14:144.

13. Heliövaara M. Occupation and risk of herniated lumbar intervertebral disc or sciatica leading to hospitalization. J Chronic Dis 1987;40:259-264.

14. Heliövaara M, Mäkelä M, Knekt $P$, Impivaara $O$, Aromaa A. Determinants of sciatica and low-back pain. Spine 1991;16:608-614.

15. Hrubec Z, Nashold BS Jr. Epidemiology of lumbar disc lesions in the military in World War II. Am J Epidemiol 1975;102:367-376.

16. Jørgensen S, Hein HO, Gyntelberg F. Heavy lifting at work and risk of genital prolapse and herniated lumbar disc in assistant nurses. Occup Med 1994;44:47-49.

17. Kaila-Kangas L, Leino-Arjas P, Karppinen J, Viikari-Juntura E, Nykyri E, Heliövaara M. History of physical work exposures and clinically diagnosed sciatica among working and nonworking Finns aged 30 to 64. Spine 2009;34:964-969.

18. Kaila-Kangas L, Miranda H, Takala EP, et al. The role of past and current strenuous physical work in the association between professional car driving and chronic lowback syndromes: a population-based study. Spine 2011;36:E734-E403.

19. Kelsey JL, Hardy RJ. Driving of motor vehicles as a risk factor for acute herniated lumbar intervertebral disc. Am J Epidemiol 1975;102:63-73.

20. Kelsey JL. An epidemiological study of the relationship between occupations and acute herniated lumbar intervertebral discs. Int J Epidemiol 1975;4:197-205.

21. Kelsey JL. An epidemiological study of acute herniated lumbar intervertebral discs. Rheumatol Rehabil 1975;14:144-159.

22. Kelsey JL, Githens PB, White AA III, et al. An epidemiologic study of lifting and twisting on the job and risk for acute prolapsed lumbar intervertebral disc. J Orthop Res 1984;2:61-66.

23. Kostova V, Koleva M. Back disorders (low back pain, cervicobrachial and lumbosacral radicular syndromes) and some related risk factors. J Neurol Sci 2001;192:17-25.

24. Palmer KT, Griffin M, Ntani G, et al. Professional driving and prolapsed lumbar intervertebral disc diagnosed by magnetic resonance imaging: a case-control study. Scand J Work Environ Health 2012;38:577-581.

25. Riihimäki H, Wickström G, Hänninen K, Luopajärvi T. Predictors of sciatic pain among concrete reinforcement workers and house painters: a five-year follow-up. Scand J Work Environ Health 1989;15:415-423.

26. Roquelaure Y, Fouquet N, Ha C, et al. Epidemiological surveillance of lumbar disc surgery in the general population: a pilot study in a French region. Joint Bone Spine 2011;78:298-302.

27. Saftić R, Grgić M, Ebling B, Splavski B. Case-control study of risk factors for lumbar intervertebral disc herniation in Croatian island populations. Croat Med J 2006;47:593-600

28. Seidler A, Bolm-Audorff U, Siol T, et al. Occupational risk factors for symptomatic lumbar disc herniation: a case-control study. Occup Environ Med 2003;60:821-830.

29. Seidler A, Bergmann A, Jäger M, et al. Cumulative occupational lumbar load and lumbar disc disease: results of a German multi-center case-control study (EPILIFT). BMC Musculoskelet Disord 2009;10:48.

30. Sørensen IG, Jacobsen P, Gyntelberg F, Suadicani P. Occupational and other pre dictors of herniated lumbar disc disease-a 33-year follow-up in the Copenhagen male study. Spine2011;36:1541-1546.

31. Virtanen IM, Karppinen J, Taimela S, et al. Occupational and genetic risk factors associated with intervertebral disc disease. Spine 2007;32:1129-1134.

32. Wahlström J, Burström L, Nilsson T, Järvholm B. Risk factors for hospitalization due to lumbar disc disease. Spine 2012;37:1334-1339.

33. Zhang YG, Sun Z, Zhang Z, Liu J, Guo X. Risk factors for lumbar intervertebral disc herniation in Chinese population: a case-control study. Spine 2009;34:E918-E922.

34. Zhang YG, Zhang F, Sun Z, et al. A controlled case study of the relationship between environmental risk factors and apoptotic gene polymorphism and lumbar disc herniation. Am J Pathol 2013;182:56-63.

35. Hill AB. The environment and disease: association or causation? Proc R Soc Med $1965 ; 58: 295-300$. 


\section{Neurology}

\section{Work-relatedness of lumbosacral radiculopathy syndrome: Review and dose-response meta-analysis}

P. Paul F.M. Kuijer, Jos H. Verbeek, Andreas Seidler, et al.

Neurology 2018;91;558-564 Published Online before print August 17, 2018

DOI 10.1212/01.wnl.0000544322.26939.09

This information is current as of August 17, 2018

\section{Updated Information \& Services}

References

Subspecialty Collections

Permissions \& Licensing

Reprints including high resolution figures, can be found at: http://n.neurology.org/content/91/12/558.full

This article cites 35 articles, 2 of which you can access for free at: http://n.neurology.org/content/91/12/558.full\#ref-list-1

This article, along with others on similar topics, appears in the following collection(s):

Class I

http://n.neurology.org/cgi/collection/class_1

Disc disease

http://n.neurology.org/cgi/collection/disc_disease

Harm/ risk (analysis)

http://n.neurology.org/cgi/collection/harm_risk_analysis

Risk factors in epidemiology

http://n.neurology.org/cgi/collection/risk_factors_in_epidemiology

Information about reproducing this article in parts (figures,tables) or in its entirety can be found online at:

http://www.neurology.org/about/about_the_journal\#permissions

Information about ordering reprints can be found online:

http://n.neurology.org/subscribers/advertise

Neurology ${ }^{\circledR}$ is the official journal of the American Academy of Neurology. Published continuously since 1951, it is now a weekly with 48 issues per year. Copyright Copyright ( 2018 The Author(s). Published by Wolters Kluwer Health, Inc. on behalf of the American Academy of Neurology.. All rights reserved. Print ISSN: 0028-3878. Online ISSN: 1526-632X.

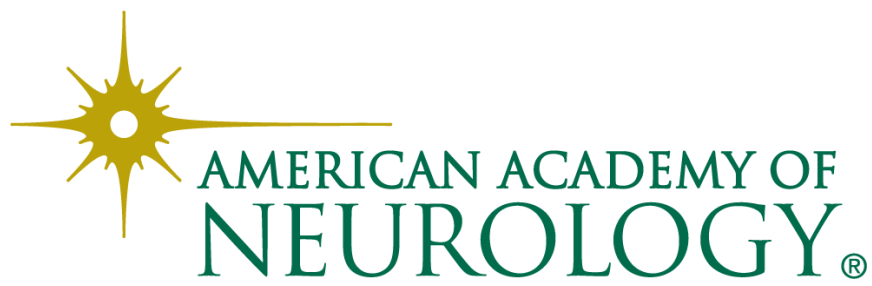

